\title{
Suicidal Behaviors in Teenagers-Building Connections from a Clinical Scenario
}

\author{
Rashid RS and Sarmad Muhammad Soomar* \\ School of Nursing and Midwifery, Pakistan
}

\begin{abstract}
Suicide is a growing issue of teenagers around the globe and also commonly seen in context of Pakistan. On regular basis we read in news or hear from people about huge number of suicides in many parts of Pakistan. The paper is written on the account of witnessing a young mental health client in psychiatry in patient services at a tertiary care hospital. The case was a huge learning for young healthcare professionals and novice nurses.
\end{abstract}

ISSN: 2640-9666

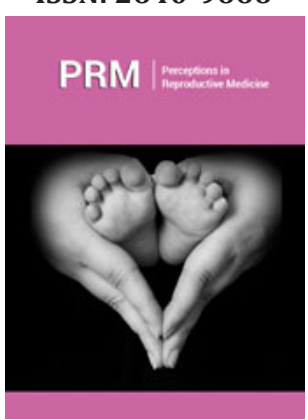

*Corresponding author: Paul T E Cusack, BScE, DULE, Saint John, Canada

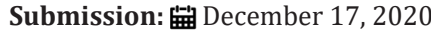

Published: 㘹January 12, 2021

Volume 4 - Issue 2

How to cite this article: Rashid RS and Sarmad Muhammad Soomar*. Suicidal Behaviors in Teenagers-Building Connections from a Clinical Scenario. 4(3). PRM. 000586. 2020

DOI: $10.31031 /$ PRM.2021.04.000586

Copyright@ Sarmad Muhammad Soomar, This article is distributed under the terms of the Creative Commons Attribution 4.0 International License, which permits unrestricted use and redistribution provided that the original author and source are credited.
Keywords: Suicide, Teenagers, Depression

\section{Introduction}

Cases related to suicide attempts are increasing in globally. Teenagers are the common victims of suicide. The situation has grown in Pakistan with time and many of young people have attempted and completed suicide. Every day, many people commit suicide that means in every 40 seconds, one person leave the world because of suicide attempt. It is fifteenth leading cause of death in teenagers from age 15 to 29 according to World Health Organization [1]. Suicide is the act of willingly, deliberately, and decisively taking one's own life [2]. In Pakistan, no proper studies have been done on suicide therefore, national data isn't reported explicitly. However, WHO in 2002, published that about 15000 suicides are committed in Pakistan in a year [3]. Alarming increase in teenage suicides is an indication that mental health professionals should work on it. It has been observed that people who suffer through an agony inside are more prone to develop suicidal behavior. This impairment in mental and physical health is one of the chief factors contributing to suicidal behavior [4].

\section{Clinical Encounter}

A young client in psychiatry in patient services at a tertiary care hospital verbalized that she had previously tried to harm herself because of her childhood memories which hinder her to move on. In her childhood, she suffered sexual abuse from the age of 8 and she was bullied by her friends at her school. She also faced parental negligence since she was 6 years old. According to her parents, she is aggressive and hyperactive child since birth. She felt lifeless and unworthy about her existence and no one appeared in front of her as hope. That hopeless situation coerced her to kill her for the sake of peace and she tried to attempt suicide without any second thought in her mind. Her unsuccessful attempt is still in her mind and it triggers her to commit again.

\section{Causes and Manifestations of Suicidal Behavior in Teenagers}

There are numerous risk factors that causes a person to have this behavior. Few of them are:

\section{Poor coping skills}

When a person doesn't have enough coping mechanism, he is easily trapped by suicidal thoughts and it seems to be the last option. Suicide is one of the maladaptive cathartic method to get rid of multiple stresses at a time [5].

\section{Trauma like sexual or physical abuse}

There are women who suffer through domestic violence and end up their lives to escape from fearful environment. People being raped or molested feels guilty for their existence and commit suicide in fear of facing the cruel society. Girls who had experienced continuous 
sexual abuse since childhood sometimes feel weak and develop low self-esteem. They also feel like being objectified as an emblem of misery. Later on, in their lives, it is difficult for them to form long term relations and they have trust issues. These problems cross the surface of sub-conscious mind and person may entangle into suicidal thoughts [6].

\section{Physical illness and chronic pain}

Person may wishes to escape the reality when he knows about poor prognosis of his illness. He also thinks that death is better than living with chronic illness. He might give up on his health because of expensive and incurable disease and try to sort of his problem by attempting suicide [7]. There are many other risk factors as well that compel a person for suicidal attempt. Few of them are not preventable and needs to be deal with courtesy and complete attention. These causes/risk factors trigger a person to behave suicidal [8]. There are some common symptoms to identify whether a person is suicidal or not. These sign and symptoms need to be addressed. A person who talks about suicide wants to commit it and is actually giving clues. Suicidal behavior is cry for help without uttering a word. Person possessing suicidal behavior gives verbal as well as non-verbal warnings. His level of impulsivity is high, he feels unworthy, hopeless and helpless. He may or may not speak about his suicidal plans. A nurse should explore if the person is having an active plan to execute. Other symptoms include, apathy, lack of interest, depressed mood, lethargy, giving away your valuable things and texting goodbye text to loved ones. Sometimes person may not intent to kill his self but wants to attain sympathy, attention or satisfaction therefore, he develops suicidal behavior but he never tries to commit or attempt suicide. There are theories related to suicide which will aid to better understand the complex phenomenon of suicide and suicidal behavior $[9,10]$.

\section{Theories Related to Suicidal Behaviors in Teenagers}

\section{The three-step theory (3ST)}

The three-step theory is an ideation to action framework that explain how a person develops suicidal behavior and that behavior develops into suicide attempt. Hopelessness, connectedness and suicide capacity are the fundamental concepts of this theory that makes it sensible to understand. Step one is when a person is in pain and feels hopeless, he develops suicidal ideation. If he has enough coping mechanism and somehow copes to come out of that pain, he doesn't develop these ideations but once the suicidal ideations are there, person can potentially develop lethal suicidal behavior. This is step two when pain exceeds the connectedness. It occurs when a person unconsciously gives more attention to his pain and forgets his connection with other realities [11]. For example, a person is fired from his job and feels hopeless; he is at risk of suicide. He develops suicidal ideations but doesn't mean he will attempt suicide. If he has good connection with his love ones, friends, and children then he can cope up with that condition. Although the ideations will be there because of hopelessness but he won't give up because connectedness is far higher than his pain. On the other hand, there is a person who is also fired from his job. He thinks that he should kill his self and he have strong desires to kill if he gets a chance because pain is greater than his connectedness. Both persons have suicidal ideations, but the difference is, one has moderate ideations while other person has strong ideations.

Person with moderate ideations do not attempt suicide at the moment [12]. Third step of 3ST model is based on suicide capacity. If the person has strong ideation, he will attempt suicide. It is difficult for majority of people to terminate their life because fear of death is a strong prevailing instinct. Yet, a person with strong ideations ignores that instinct and only thinks of his unbearable pain. This constant agonizing and intolerable pain provide them courage and negative energy to attempt suicide. According to several other researches, there are additional factors that contribute to suicide attempt like genetic component, lower pain sensitivity by birth and easy access to means by which a person can commit suicide [13].

\section{The interpersonal-psychological theory of suicidal behavior}

This theory elucidates suicidal behavior of a person who wants to die and a person who can die by suicide. It discusses that the suicidal behavior is not just confined to ideations, an individual with strong ideation and capability commits suicide. The desire to commit suicide comprises of two interpersonal states: perceived difficulty to carry a situation and dissatisfied belongingness. Conjunction of these two states results in suicide [14]. Perceived difficulty means to feel that the self in incompetent to live and is burden on the earth. It motivates an individual to belief that he has no right to live because he is cause of all the problems. Person with this perilous misperception about his self develops guilt and suicidal behavior. It is an intolerable situation which advances from repetitive exposure to pain and provoking events. This perceived difficulty give rise to acquire capability for suicide whereas, the dissatisfied belongingness means to feel frustrated for your belongings [15]. For example, a person being bullied at her school perceives difficulty to carry on and feel dejected by society. At the same time, she thinks that she has bad dressing sense; she is fat, ugly, estranged and has pitiable body image. These displeasing thoughts about her belongings refer to dissatisfied belongingness which causes suicidal behavior. This theory also confers about self-harming behavior that progress to suicide. A person caged in a situation where he feels lifeless, harms his self to feel the life. These potential self-injurious attitudes give him temporary relief and he feels tranquil for it. To mend his sorrows and worries he can also think of a permanent solution that is suicide. It means that repeated and provocative experience of self-injury create a sense of fearlessness and courage about death. It provokes a person to attain suicidal capacity and hence, increases the risk for suicide [16]. There are many practical ways to engage in self-injury such as burn, cuts, taking drugs etc. According to this theory, major risk factors for suicide attempts are depression, hopelessness and borderline 
personality disorder features [17]. In my clinical scenario, patient was also suffering from borderline personality disorder and tried to commit suicide. Furthermore, the raised level of aggression increases the risky behavior. It is correlated with higher prenatal testosterone level and decreased levels of nor epinephrine [18].

\section{Recommendations \& Conclusion}

Provide support to individuals who are sad and require help. Don't be afraid to directly ask about suicidal ideations. Provide opportunities of developing resilience in young children and teenagers. As an individual, we can work on such behaviors in order to decrease suicide rates of our country. Most of the teenagers are unable to express their pain in front of their family and the reason is generation gap, poor understanding, negligence or spending more time in other social gatherings than family. That is why friends and other social support, good parenting, free psychological services are important. Insurance for psychiatric illness, mental health leaves and ventilation spaces are necessary to be developed. Collaborative approach of teachers, doctors, family and friends can do wonders for young people. Suicidal behaviors in teenagers is a rising and significant concern of today's world that needs to be addressed. Anyone can possess destructive and suicidal behavior that not only harms them but also affects the people around them. We are well aware of the alarming signs that are linked with suicidal behavior therefore, it is our core responsibility to explore and critically observe all the dimensions that sets a person at risk of suicide then we should plan practical and effective interventions to help people out of that situation and to identify positive coping mechanisms.

\section{References}

1. World Health Organization (2014) Preventing suicide: A global imperative. Geneva, Switzerland.

2. World Health Organization (2000) Preventing suicide: A resource for teachers and other school staff.

3. World Health Organization (2002) Preventing suicide: A resource for counsellors. Geneva, Switzerland.

4. Stuart GW (2014) Principles and practices of psychiatric nursing.
5. World Health Organization (2016) Preventing suicide.

6. Lochman JE, Barry T, Powell N, Young L (2010) Anger and aggression. In Practitioner's guide to empirically based measures of social skills.

7. World Health Organization (2006) Preventing suicide.

8. Boyd MA (2012) Psychiatric nursing: Contemporary practice.

9. Twenge JM, Joiner TE, Rogers ML, Martin GN (2018) Increases in depressive symptoms, suicide-related outcomes, and suicide rates among US adolescents after 2010 and links to increased new media screen time. Clinical Psychological Science 6(1): 3-17.

10. Hogstedt C, Forsell Y, Hemmingsson T, Lundberg I, Lundin A (2018) Psychological symptoms in late adolescence and long-term risk of suicide and suicide attempt. Suicide and Life-Threatening Behavior 48(3): 315-327.

11. Klonsky ED (2018) Toward a parsimonious understanding of suicide: Comparing the three-step theory to Malhi and colleagues integrated model. Bipolar Disorders 20(6): 568-569.

12. Dhingra K, Klonsky ED, Tapola V (2019) An empirical test of the threestep theory of suicide in UK university students. Suicide and LifeThreatening Behavior 49(2): 478-487.

13. Klonsky ED, Saffer BY, Bryan CJ (2018) Ideation-to-action theories of suicide: a conceptual and empirical update. Curr Opin Psychol 22: 38-43.

14. Batterham PJ, Walker J, Leach LS, Ma J, Calear AL, et al. (2018) A longitudinal test of the predictions of the interpersonal-psychological theory of suicidal behaviour for passive and active suicidal ideation in a large community-based cohort. J Affect Disord 227: 97-102.

15. Swit CS (2019) Understanding the distinctive differences between relationally and physically aggressive behaviours used in early childhood contexts. Early Education and Development 28: 1-20.

16. Bryan CJ, Wood DS, May A, Peterson AL, Wertenberger E, et al. (2018) Mechanisms of action contributing to reductions in suicide attempts following brief cognitive behavioral therapy for military personnel: a test of the interpersonal-psychological theory of suicide. Arch Suicide Res 22(2): 241-253.

17. King JD, Horton SE, Hughes JL, Eaddy M, Kennard BD, et al. (2018) The interpersonal-psychological theory of suicide in adolescents: A preliminary report of changes following treatment. Suicide Life Threat Behav 48(3): 294-304.

18. Björkqvist K (2018) Gender differences in aggression. Curr Opin Psychol 19: $39-42$ 